\title{
Gaming the System: Practices against the algorithmic makeover of everyday life
}

\author{
Daniel Cermak-Sassenrath \\ IT-University \\ Copenhagen \\ dace@itu.dk
}

\begin{abstract}
The introduction of technical, algorithmically-controlled interactive medial systems into virtually all contexts of everyday life is a relatively recent phenomenon. Implications, for instance, for social and political contexts are still emerging. One probably unexpected but certainly unintended effect is the emergence of gaming the system behaviours. Gaming is seen here as participants taking advantage of systems by interacting with them in unintended ways to gain unjustified benefits. These behaviours are regularly seen as problematic, and measures to prevent or to detect and to react to them are discussed in the academic discourse. This study aims to establish characteristics, practices and causes of such behaviours, exemplatory in the area of interactive, educational tutoring systems. The study is informed by positions from Game Studies, Cognitive Evaluation Theory (CET; Deci, Ryan) and the (post-) phenomenological discourse on the intentionality of non-human actors. It finds that users feel disenfranchised rather than empowered by the intentionality embodied in algorithmic systems; that those systems afford play; and that gaming behaviour can be read as defensive and evasive, rather than aggressive and criminal.
\end{abstract}

Algorithms. Appropriation. Education. ITS. Learning. Media. Play. Politics. Software. Subversion.

\section{INTRODUCTION}

This study sets out to establish characteristics, practices and causes of gaming the system behaviours. The text offers definitions of the notions of system and of gaming behaviours, before it focuses on a specific example which appears to be a prime context of gaming behaviours: technically-mediated, real-time, interactive educational systems.

The hypothesis is, that users regularly feel disenfranchised rather than empowered by the intentionality embodied in systems; that algorithmic systems afford play, and that gaming behaviours can be read as defensive and evasive, rather than aggressive and criminal.

This text presents a three-part argument; it shows that systems are not neutral but embody (human) intentions and understandings; that external incentive systems undermine people's intrinsic motivations; and that digital, interactive media exhibit a propensity for play.
The investigation is informed by positions from Game Studies, Cognitive Evaluation Theory (CET) (Deci, Ryan) and the (post-) phenomenological discourse on the intentionality of non-human actors.

\section{DEFINITIONS}

An attempt is made to define the notions of system and of gaming the system for the purpose of this study.

\subsection{System}

Perrow employs a wide notion of systems; they can scale from the private sphere to the public, business, industrial and scientific. Systems can be small and large, and they can overlapi (1999:64), and even change depending on context (ibid.:96f.). Salen and Zimmerman offer as examples of systemic forms 'mechanical and mathematical systems' and 'conceptual and cultural ones' (2004:50). 
The notion of systems is here seen to refer to manmade structures of relationships or interdependencies. Systems can be facilitated through technical and non-technical means (such as a public authority). Main characteristics of systems identified here are:

(i) They abstract, quantify and categorize; rather than explain or negotiate.

(ii) They are not neutral, but human agency informs them (e.g. their functional design) or is transferred to them.

(iii) They involve inherent, automatic, emergent behaviour, for example, through mechanical or organizational connections.

This study focusses on systems which, in addition:

(iv) have outcomes or results (e.g. test scores);

(v) offer their users incentives, tangible rewards, benefits, gains and sanctions (e.g. money);

(vi) are not under control of their users (who are recipients or participants rather than authors);

(vii) are real-time interactive (this implies, they are not hidden, and users are aware of them);

(viii) are technically (i.e. algorithmically) mediated.

\subsection{Gaming the system}

Generally, '[t]he phrase 'gaming the system" (Bay, Sjödin \& Mcgoun 2011:5) refers to behaviours designed to 'tak[e] advantage of the system; that is to say, specifically turning something performing a productive social function to one's own enjoyable ends' (ibid.). In the cases in which participants perceive a system as unjust or dysfunctional, they might see gaming as a legitimate way to produce useable or desirable results.

Practices of gaming the system are seen here as being characterized by three moments:

(i) Participants interact with systems in unintended ways (for instance, they exploit programming bugs, decode question structures, overuse automated help functions, employ trial-and-error strategies, circumvent control or validation mechanisms, and tune parameters).

(ii) Participants aim to aquire (perceived) advantages or benefits. ${ }^{\text {ii }}$

(iii) The participants' goals mis-align with the systemic goals (for instance, the gains are unjust, e.g. unearned).iii

The above definition centres around an observational core rather than to establish hard boundaries on the outside. Below and beyond gaming behaviours exist similar behaviours that might interface and overlap with them.

Below gaming lie compliant behaviours of acceptance and adjustment. If some parameters are sanctioned in a system over others, participants might simply give way to the pressure and adapt to them, however much or little sense they might make. To follow e.g. organisational pressure to perform in certain ways might be simply seen as complying with the rules.

Beyond gaming lie illegal practices. When participants game a system, they trespass against the spirit of the (e.g. social) arrangement that relies on the good faith of its participants, but not against its (e.g. technical or legal) rules (Baker et al. 2004:384). Particpants 'bypass the [systemic] rules while ostensibly honoring them' (Morreim 1991:443). Cheating in classroom tests and stealing exam questions are examples of more explicit, rule-breaking behaviours or even illegal practices.

But it might only be a small step or a change of perspective from strategically exploiting systemic properties or faults, from 'taking advantage of loopholes in a system' (Baker et al. 2004:384), to outright cheating it; 'the stretch and push' of creative manipulations of a system using its flexibilities and ambiguities then 'merges into the flagrant dishonesty of fraud' (Morreim 1991:444; see Baker et al. 2004:384).

Systems which have been investigated with regard to them being gamed by their participants include Amazon's Mechanical Turk online marketplace (Downs et al. 2010), the US and UK health care systems (Morreim 1991; Bevan \& Hood 2006), and the US public school system (Figlio \& Getzler 2002). Other areas suspectable to gaming are the spending of funds in organisations, the tuning web sites for high placements in search engines, and gambling for money. 


\section{CASE STUDY: INTERACTIVE, EDUCATIONAL TUTORING SYSTEMS}

The area selected here for an examplatory analysis is the educational use of interactive tutoring systems; an application in which gaming behaviours have 'been repeatedly documented' (Baker et al. 2006a:392; see Baker et al. 2009:475). Interactive tutoring systems 'are one of the more successful and widely-used approaches to incorporating computer-aided instruction into the classroom' (Baker et al. 2004:383), and 'intelligent tutors are increasingly being used as major components in year-long curricula' (Baker et al. 2006b:402).

In the context of the use of interactive learning tools, gaming the system is usually seen as a set of student behaviours attempting to exploit properties such as regularities of an educational system rather than 'to engage in meaningful thought' about the subject matter (Baker et al. 2004:389) to 'obtain [...] correct answers and [to] advanc[e] within the tutoring curriculum' (ibid.:383) 'quickly and easily [...] with little or no work' (Walonoski, Heffernan 2006:382).

The educational use of 'cognitive tutoring system[s]' (Baker et al. 2004:383), 'intelligent tutoring systems' (ITS; Walonoski \& Heffernan 2006:382; Baker et al. 2006a:392) or 'computer tutor[s]' (Baker et al. 2005:59) is usually combined with traditional teaching; (human) teachers offer 'conceptual instruction' (Baker et al. 2004:383), and computer tutors offer interactive 'problem-solving' (ibid.). The tutors are used supervised (in the classroom) or unsupervised (in the school's computer labs or outside the school (Baker, Mitrovic \& Mathews 2010:272)). While students talk to each other and the teacher on-topic and offtopic, the use of tutors is 'solitary' work (Baker et al. 2004:386; see p. 383).

\subsection{Extend of gaming}

The frequency of gaming behaviours is variously reported to be low or high. In three studies conducted by Baker and colleagues (2004; 2006a; 2010 ), they find that only about $1 / 3$ of students are 'observed gaming the system even once. By comparison, $51 \%$ of students were observed engaging in other types of off-task behavior at least once' (2004:387).

In contrast, Murray and VanLehn (2005:887) report that gaming is '[a] scourge of the ITS field'. A study by Walonoski and Heffernan finds that considerable numbers of students game. 'Out of 365 students, 53 were very-high gamers, 91 were aboveaverage, 179 were below-average, and 42 were very-low gamers.' (2006:388) Walonoski and
Heffernan posit that specifically 'performancebased gaming' is a 'major issue' in students' offtask student behavior' when using 'Intelligent Tutoring Systems' (ibid.:382), and that the 'positive effect on student learning' that interactive tutors 'have been shown to have [...] may be negated by a lack of student motivation or student misuse' (ibid.).

It has been observed by Mostow et al. (2002) 'that some students take advantage of learner-control features of a reading tutor to spend the majority of their time playing rather than working' (Baker, Corbett \& Koedinger 2004:532, emph. added).

\subsection{Effects on learning}

Baker et al. (2004:383; see Baker et al. 2005:57) report that 'no other type of off-task behavior is associated nearly so strongly with reduced learning as 'gaming the system". One study finds that 'students who frequently gamed learned $38 \%$ less than students who never gamed' while 'off-task behaviors such as talking to neighbors [...] or surfing the web were not negatively correlated with learning' (Baker et al. 2005:58; see Baker, Corbett \& Koedinger 2004:531).

But the causal relationship between gaming behaviours and low learning rates is not undisputed. Gaming might lead to low academic achievements, and/or low-achieving students might engage in gaming. A study by Baker et al. shows that students who engaged often in gaming behaviours not only perform significantly lower on a post-test than students who never game (2004:386f.), but they also start with 'lower pretests' (ibid.:387). Students who started with low pretest scores but did not game 'learned considerably more than students who gamed the system' (ibid.:387f.). A later study (Baker et al. 2006a) confirms these observations.

Results of Walonoski and Heffernan's study 'suggest that the learning rates of students who game and those that do not are reasonably different than mere chance alone' (2006:389), with higher learning rates for non-gaming students (ibid.). Their 'results very strongly indicate that students who engage in gaming' (ibid.:390) have 'lower prior knowledge than other students' (ibid.); they also find 'that gamers do not perform well on the actual MCAS state administered mathematics exam' (ibid.).

However, Baker (2007:76) 'suggest[s] that gaming the system can be generally better understood through state explanations than trait explanations'; that means that gaming spontaneously emerges in certain learning situations rather than to be a characteristic of individual students. Baker et al. 
(2009:476) posit that 'thus far, the evidence seems weak for the belief that individual differences [between students] are the major factor explaining gaming'.

\subsection{Practices}

The practices associated with gaming behaviours in interactive, educational tutoring systems appear to centre around three strategies: '[H]elp abuse' (Baker, Corbett \& Koedinger 2004:532), 'systematic guessing' (Walonoski \& Heffernan 2006:383) or 'systematic trial-and-error' (Baker, Corbett \& Koedinger 2004:532), and 'soft underbelly strategies' (Baker, Mitrovic \& Mathews 2010:272).iv

An example for the first type of behaviour is 'quickly and repeatedly asking for help until the tutor gives the student the correct answer' (Baker et al. 2004:383), to 'rapidly repeat [...] the same answer or blank answers to elicit answers' (Baker, Mitrovic \& Mathews 2010:267), or to make '[i]ntentional rapid mistakes' (Baker, Mitrovic \& Mathews 2010:271); these practices are also known as 'bottom-out hint requests' (Walonoski \& Heffernan 2006:384) or 'rapid-fire hint requests' (Baker et al. 2006a:393). An example for the second type of behaviour is 'inputting answers quickly and systematically. For instance, entering $1,2,3,4, \ldots$ or clicking every checkbox within a set of multiplechoice answers' (Baker et al. 2004:383) 'until an answer is identified as correct by the system' (ibid.:385). An example for the third type of behaviour is to 'repeatedly switch [...] problems to try to find an easier problem to work on' (Baker, Mitrovic \& Mathews 2010:271).

\subsection{Counter measures}

'[l]ntervention strategies' (Walonoski \& Heffernan 2006:383) in educational, interactive tutoring systems can be 'developed and deployed' as preventive or reactive measures. Preventive measures aim 'to make it more difficult for students to game the system' (Baker et al. 2004:388). This is achieved, for instance, by 'simply redesigned tutor interfaces' (ibid.). Common implementations include 'multi-level help [...] instead of just giving students the answer on demand' (ibid.), 'lessons [...] without 'bottom-out' hints' (ibid.), hints 'with a time delay before the student can request each successive level of help, in order to encourage students to read each level of the help' (ibid.), 'not give help until a student ha[s] spent a minimum amount of time on the current problem' (Baker et al. 2006a:393), and 'mandatory hints ('proactive help') when a student commits more than three errors on a single step, preventing systematic guessing' (ibid.).
Much work has recently been invested and 'increasing attention has been paid' (Baker, Mitrovic \& Mathews 2010:267) with the aim to develop educational software which can 'recognize and adapt to' (ibid.) students' gaming behaviours, for it to be able 'to select which students receive interventions to reduce gaming' (ibid.), and to 'extend the benefits of gaming intervention to more topics and a greater number of students' (Baker, Mitrovic \& Mathews 2010:268). While researchers are aware that simply to make gaming more difficult or costly for students does not address underlying motives (Baker et al. 2005:63), the discourse appears to remain within the paradigm of using technically-mediated automatic educational tools. The common approach appears to be to revise 'elements of [the computer tutor's] presentation' (Baker et al. 2004:389) with the aim to 'maximize tutor effectiveness' (Walonoski, Heffernan 2006:382).

Paradoxically, students game algorithmic systems, and algorithmic systems are developed which detect this. Consequently, Baker et al. (2004:389) speculate that 'trying to redesign tutors to directly prevent students from gaming the system may lead to an arms race, with students figuring out new ways to game the system in response to our redesigned tutors'. Comparing two educational tutoring systems of which one was equipped with a ten second help delay, Murray and VanLehn (2005:889) indeed 'observed a few instances of a new type of help abuse' in the delayed system.

\subsection{Reasons}

Many explanations are proposed as to why students game the educational systems they are given; for instance, a lack of interest in the material' (Baker et al. 2004:389); 'learned helplessness' (ibid.:383); low ability (Baker, Corbett \& Koedinger 2004:533; Baker et al. 2006a:400); 'anxiety, [...] the belief that they cannot succeed otherwise' (Baker et al. 2005:58); computer anxiety (ibid.:60); 'performance goals' (Baker et al. 2004:383; Martínez Mirón, du Boulay \& Luckin 2004 in Baker et al. 2005:58), that is, '[s]tudents [...] focusing on performing well rather than learning' (Baker et al. 2005:58); emerging states of confusion and boredom (Baker et al. 2009:481); a dislike of computers (Baker et al. 2005:61); and a dislike of computer tutors (ibid.).v

It seems that of these explanations, several are already disconfirmed by empirical research. Baker et al. (2004:389) 'conclude with fairly high confidence that lack of interest in the material is unlikely to be a good explanation of why students game the system'. It has also been shown that gaming 'appears to not be associated with [students] having performance goals or anxiety, 
contrary to earlier predictions' (Baker et al. 2005:63).

The explanations that are most relevant to and inline with the argument made in this text, might be, that in this specific context, gaming happens as a reaction to the use of computers and of computer tutors. Baker et al.'s study found that '[s]tudents who gamed [...] liked computers significantly less than the other students [...] and liked the tutor significantly less than the other students' (2005:60). Baker et al. offer the interpretations 'that a student who has a negative attitude towards computers and the tutor may believe that a computer cannot really give educationally helpful hints and feedback - and thus, when the student encounters material she does not understand, she may view gaming as the only option'; that 'a student may believe that the computer doesn't care how much he learns, and decide that if the computer doesn't care, he doesn't either'; and 'that a student may game as a means of refusing to work with a computer she dislikes, without attracting the teacher's attention'(ibid.:61).

\section{INTENTIONALITY}

The notion of intentionality decribes in a phenomenological context the directedness of meaning and of actions, and the designed effects of actions. While not claiming that artefacts would 'have intentions' or could 'be held responsible for what they do', Verbeek (2005:7) emphasizes that things 'do act'. He observes them to 'play a mediating role - one with an ethical dimension in that moral considerations are transformed, shaped or even taken over'. He explains (2010:6) how the mediating function of the world artefacts perform, is a translation of action as pointed out by Latour: '[W]hat humans do is co-shaped by the things they use. Actions are not only the result of individual intentions and the social structures in which these individuals find themselves [...], but also of people's material environment.' He offers the example of a speed bump which very tangibly 'translates a driver's intention' from considering saving time or showing resposible behaviour, to 'driving slowly to save [his or her] shock absorbers'.

Thus, similar to other artefacts, systems are not neutral, but express and reflect certain values, world-views, philosophical positions and political convictions, specifically when they facilitate and sanction certain behaviours.

\section{MOTIVATIONS}

To introduce incentive-based systems into e.g. organisational or educational contexts has implications for people's motivations. Deci et al. (2001:3) explain that, according to CET, intrinsic motivation is supported by 'the innate psychological needs for competence and self-determination'. In case of events 'that lead to a more external perceived locus of causality', people's perceived decrease in self-determination 'undermine[s their] intrinsic motivation'; whereas events 'that increase [people's] perceived self-determination (i.e., that lead to a more internal perceived locus of causality) will enhance [their] intrinsic motivation'. In addition, 'events that increase perceived competence will enhance intrinsic motivation so long as they are accompanied by perceived self-determination [...], and those that decrease perceived competence will diminish intrinsic motivation'.

CET predicts that incentives such as rewards 'have two aspects' (Deci, Koestner \& Ryan 2001:3) that can lead to people to feel either 'feel competent and in control' or to 'feel powerless and incompetent' (Hanus \& Fox 2015:153): While '[t]he informational aspect conveys self-determined competence and thus enhances intrinsic motivation [...], the controlling aspect prompts an external perceived locus of causality (i.e., low perceived self-determination) and thus undermines intrinsic motivation' (Deci, Koestner \& Ryan 2001:3).

Giving out desirable, 'tangible rewards (including material rewards, such as money and prizes, and symbolic rewards, such as trophies and good player awards)' counts towards controlling behaviour and decreases intrinsic motivation (Deci, Koestner \& Ryan 2001:9). Computer tutors in educational contexts might plausibly be perceived by students as controlling when they 'highly effective[ly]' assess students' skills and select exercises for them (Baker, Corbett \& Koedinger 2004:531), or when an Office assistent-style onscreen character (Baker et al. 2006a:393f.) 'both serves as a[ ]continual reminder that the student should not game, and lets teachers know which students were gaming recently' and is intended 'to invoke social norms in students by expressing negative emotion when students game', and 'giv[es] students supplemental exercises targeted to the material the student was gaming through' i.e. 'extra work' (ibid.).

While many instances of gaming behaviours might occur for quite mundane and concrete reasons or plainly happen at occasions of confusion or boredom, the underlying motive of people engaging in gaming behaviours may be seen as a defensive, opportunistic or mischievous reaction to or effect of the increasing algorithmicalization or algorithmic makeover of life. People may engage in gaming behaviours not because of subversive attitudes or criminal intentions, but because their intrinsic motivations are compromised from without. 


\section{IS IT PLAY?}

Digital, interactive media such as the computer exhibit a propensity for play. Cermak-Sassenrath (2010:98) argues that '[t]he interaction with the computer has always been playful' and that the expansion in users' competences broadens this perspective from a niche approach to mainstream behaviour. He cautions, though, that the 'interaction [...] always stand[s] at a crossroads between an efficient, controlled and purposeful use and playful, free and self-controlled interaction'. But although everyday computer usage regularly 'pursue[s] goals and therefore lies outside the sphere of play [...] this computer use can still become play' when it 'overcomes [purposes] effectively'. The use of the computer can then happen as play 'despite the fact that [it] is used instrumentally'.

The introduction of systems such as computer tutors might bring play about even easier when it liberates the participants from making up their own systems of play. One characteristic property of algorithmic systems appears to be that they afford play. They conveniently introduce an abstract layer over the everyday world; for instance, they order it, quantify it, assign (un)desirable values, keep scores and track progress. In a study of gaming in an educational online communitity system, Cheng and Vassileva (2006:345) observe that '[a]n incentive mechanism evokes the 'sleeping computer gamers' in many users by providing a challenge for their ingenuity'. vi

There exist many inherent similarities of (manmade) systems and games. Games are closed, self-sufficient, self-contained, internally valid and meaningful systems. Salen and Zimmerman posit that 'games are systems' if a system is '[a] group of interacting, interelated, or interdependent elements forming a complex whole' (2004:50). Many definitions of games might fit systems, as well. For instance, Salen and Zimmerman's (2004:572) definition of games as 'system[s] in which players engage in an artificial conflict, defined by rules, that results in a quantifiable outcome'. Juul (2011:36) similarly defines a game as 'a rule-based system with a variable and quantifiable outcome, where different outcomes are assigned different values, the player exerts effort in order to influence the outcome, the player feels emotionally attached to the outcome, and the consequences of the activity are negotiable'.

\section{CONCLUSION}

The emergence of algorithmic systems in everyday contexts is arguably a novel, recent and expanding phenomenon. This text focused on technically mediated, interactive real-time systems, controlled by algorithms.

The text aimed to show that gaming behaviours can be seen as an appropriative, defensive practice against the algorithmic makeover of everyday life; it did so by arguing that systems introduce layers of abstraction into everyday life; that many users feel disenfranchised rather than empowered by the intentionality embodied in those systems; and that the systems afford play, specifically interactive realtime systems, many of which are technically mediated, and driven by algorithms.

Systems such as educational software inevitably introduce new motivations and upset the existing ones (Sailer et al. 2017:374). Hanus and Fox observe that 'a substantial body of research suggests that caution should be taken' to introduce, for instance, 'rewards, incentives, and competition' $(2015: 154)$. One clear result of Deci et al.'s metaanalysis is that 'tangible rewards do significantly and substantially undermine intrinsic motivation' (2001:2). For people who are 'initially interested in a task' or topic, the offer of an extrinsic motivational factor 'may cause them to shift motivations from intrinsic [...] to extrinsic' (Hanus \& Fox 2015:154); 'once the reward is removed [they] will no longer have a reason to perform a behavior' (ibid.). While both types of motivations move people to act, intrinsic motivation offers essential benefits over extrinsic. Extrinsic motivation such as 'rewards or punishments [...] gives rise to experiences of unwillingness, tension, and coercion' (Johnson et al. 2016:5). 'Intrinsic motivation', on the other hand, 'giv[es] rise to the experience of volition, willingness, enjoyment' (ibid.). Benefits of intrinsic motivation go beyond on-task performance (such as intensity or length of engagement, or quantifiable outcome) and include a direct contribution 'to mental and social well-being' (ibid.).

If gaming the system is a defensive or evasive reaction of users who are confronted with a technically mediated situation in which they have little agency, and which disenfranchises and separates them from their core or subject interests, one implication can be not to fit and fix the systems with clever usability designs, controls and antigaming mechanisms, but to carefully consider and critically question the neccessity for and benefits of the introduction and use of the systems.

\section{REFERENCES}

Baker, R. S. J. d. (2007) Is gaming the system state-or-trait? Educational data mining through the multi-contextual application of a validated behavioral model. Complete On-Line Proceedings of the Workshop on Data Mining for User Modeling 
at the 11th International Conference on User Modeling 2007, 2007, 76-80.

Baker, R. S. J. d., de Carvalho, A. M. J. B., Raspat, J., Aleven, V., Corbett, A. T., and Koedinger, K. R. (2009) Educational software features that encourage and discourage 'gaming the system'. Proceedings of the 14th International Conference on Artificial Intelligence in Education, 2009, 47582.

Baker, R. S. J. d., Corbett, A. T., and Koedinger, K. R. (2004) Detecting student misuse of intelligent tutoring systems. Intelligent Tutoring Systems. Proc. 7th Int. Conf., ITS 2004, 2004, 531-40.

Baker, R. S. J. d., Corbett, A. T., Koedinger, K. R., and Roll I. (2006b) Generalizing Detection of Gaming the System Across a Tutoring Curriculum. In Ikeda, M., Ashley, K. D., Chan, T.-W. (eds.). Intelligent Tutoring Systems. Proceedings 8th International Conference ITS 2006. Lecture Notes in Computer Science 4053. Springer, Berlin, 40211.

Baker, R. S. J. d., Corbett, A. T., Koedinger, K. R., Evenson, S., Roll, I., Wagner, A. Z., Naim, M., Raspat, J., Baker, D., J., and Beck, J. E. (2006a) Adapting to When Students Game an Intelligent Tutoring System. In Ikeda, M., Ashley, K. D., Chan, T.-W. (eds.). Intelligent Tutoring Systems. Proceedings 8th International Conference ITS 2006. Lecture Notes in Computer Science 4053. Springer, Berlin, 392-401.

Baker, R. S. J. d., Corbett, A. T., Koedinger, K. R., and Wagner, A. Z. (2004) Off-task behavior in the cognitive tutor classroom: When students 'game the system'. CHI Letters, 6(1), pp. 383-90.

Baker, R. S. J. d., Mitrovic, A., and Mathews, M. (2010) Detecting Gaming the System in ConstraintBased Tutors. Chapter. In De Bra, P., Kobsa, A., and Chin, D. (eds.). User Modeling, Adaptation, and Personalization. Proc. 18th Int. Conf. UMAP 2010. Lecture Notes in Computer Science 6075. Springer, Berlin, 267-78.

Baker, R. S. J. d., Roll, I., Corbett, A. T., and Koedinger, K. R. (2005). Do performance goals lead students to game the system? Proceedings of the 12th International Conference on Artificial Intelligence and Education, Amsterdam, 2010, 5764.

Bay, T., Sjödin, U., and Mcgoun, E. G. (2011) Gaming the system. Int. J. Critical Accounting, 3(1), pp. 5-17.

Bevan, G., and Hood, C. (August 2006) What's measured is what matters: Targets and gaming in the English public health care system. Public Administration, 84(3), pp. 517-38.

Cermak-Sassenrath, D. (2010) The Logic of Play in Everyday Human-Computer Interaction. In Günzel,
S., Liebe, M., and Mersch, D. (eds.). Logic and Structure of the Computer Game. Potsdam University Pr., Potsdam, 80-103.

Cheng, R, and Vassileva, J. (2006) Design and evaluation of an adaptive incentive mechanism for sustained educational online communities. User Model User-Adap Inter, 16, pp. 321-48.

Deci, E. L., Koestner, R., and Ryan, R. M. (2001) Extrinsic rewards and intrinsic motivation in education: Reconsidered once again. Rev. Educ. Res., 71, pp. 1-27.

Downs, J. S., Holbrook, M. B., Sheng, S, and Cranor, L. F. (2010) Are your participants gaming the system? Screening mechanical turk workers. Proc. CHI 2010, 2399-402.

Figlio, D. N., and Getzler, L. S. (2002) Accountability, Ability and Disability: Gaming the System? National Bureau Of Economic Research, working paper 9307 (www.nber.org/papers/w9307), October 2002.

Morreim, E. H. (March 1991) Gaming the system. Dodging the rules, ruling the dodgers. Arch Intern Med, 151, pp. 443-7.

Hanus, M. D. and Fox, J. (2015) Assessing the effects of gamification in the classroom: A longitudinal study on intrinsic motivation, social comparison, satisfaction, effort, and academic performance. Computers \& Education, 80, pp. 15261.

Johnson, D., Deterding, S., Kuhn, K.-A., Staneva, A., Stoyanov, S., and Hides, L. (2016) Gamification for health and wellbeing: A systematic review of the literature. Internet Interventions, pp. 89-106, preprint manuscript accepted for publication.

Juul, J. (2011) Half-Real. Video Games Between Real Rules and Fictional Worlds. MIT Pr., Cambridge.

Martínez Mirón, E. A., du Boulay, B., and Luckin, R. (2004). Goal achievement orientation in the design of an ILE. Proceedings of the ITS2004 Workshop on Social and Emotional Intelligence in Learning Environments, 72-8.

Mostow, J., Aist, G., Beck, J., Chalasani, R., Cuneo, A., Jia, P., and Kadaru, K. (2002) A la recherche du temps perdu, or As time goes by: Where does the time go in a reading tutor that listens? Sixth International Conference on Intelligent Tutoring Systems, 320-9.

Murray, R. C. and VanLehn, K. (2005) Effects of dissuading unnecessary help requests while providing proactive help. Proc. 12th International Conference on Artificial Intelligence in Education, 887-9. 
Perrow, C. (1999) Normal Accidents - Living with High-Risk Technologies. Princeton Univ. Pr., Princeton, 4th ed.

Sailer, M., Hense, J. U., Mayr, S. K., and Mandl, H. (2017) How gamification motivates: An experimental study of the effects of specific game design elements on psychological need satisfaction. Computers in Human Behavior, 69, pp. 371-80.

Salen, K. and Zimmerman, E. (2004) Rules of Play. Game Design Fundamentals. MIT Pr., Cambridge.

Verbeek, P.-P. (2005) What Things Do. Philosophical Reflections on Technology, Agency, and Design. Talk slides. ITU, Copenhagen, DK.

\footnotetext{
' Small systems might be part of larger; systems can overlap in part; different people can set up and maintain different systems that meet and interact with each other.

ii If participants just fool around and waste their own and the system's time, they are not gaming the system.

iii Participants who play a system, that is, are part of it, a cog in the machine, and keep it running, are taken not to (primarily) game it. For example, spin doctors are players of and in the political machine.

${ }^{\text {iv }}$ One type of computer tutor is largely uneffected by students 'systematically and rapidly trying many answers until one turns out to be correct'; in tutors that 'use [...] mastery learning, a student can only advance through the curriculum by demonstrating knowledge of the relevant problem-solving skills; the tutor infers knowledge of a skill from the student's success in responding correctly on the first try when that skill applies' (Baker et al. 2004b:388). A problem is, of course, that there is only a limited number of questions the tutor can pose to the students for the first time; another, that some students might not see the whole curriculum.

${ }^{v}$ Walonoski and Heffernan present an array of findings (2006:388f.), some of which are 'inconsistent with previous findings' (ibid.:389).

vi Interactive tutors might be an example of unintentional gamification.
}

Verbeek, P.-P. (2010) What Things Do. Philosophical Reflections on Technology, Agency, and Design. Summary. http://www.realtechsupport. org/UB/WBR/texts/markups/Veerbeck_WhatThings Do_2010_markup.pdf (retrieved 29 May 2018).

Walonoski, J. A. and Heffernan, N. T. (2006) Detection and Analysis of Off-Task Gaming Behavior in Intelligent Tutoring Systems. In Ikeda, M., Ashley, K. D., Chan, T.-W. (eds.). Intelligent Tutoring Systems. Proceedings 8th International Conference ITS 2006. Lecture Notes in Computer Science 4053. Springer, Berlin, 382-91. 